Article

\title{
Prevalence of Hearing Loss in Dutch Newborns; Results of the Nationwide Well-Baby Newborn Hearing Screening Program
}

\author{
Rosanne B. van der Zee ${ }^{1, *}$, Noëlle N. Uilenburg ${ }^{1}$, Catharina (Kitty) P. B. van der Ploeg ${ }^{2}$ and Evelien Dirks ${ }^{1,3}$ \\ 1 Dutch Foundation for the Deaf and Hard of Hearing Child (NSDSK), Lutmastraat 167, 1073 GX Amsterdam, \\ The Netherlands; nuilenburg@nsdsk.nl (N.N.U.); edirks@nsdsk.nl (E.D.) \\ 2 TNO Department of Child Health, P.O. Box 3005, 2301 DA Leiden, The Netherlands; kitty.vanderploeg@tno.n \\ 3 Department of Psychology, Utrecht University, 3584 CH Utrecht, The Netherlands \\ * Correspondence: rvanderzee@nsdsk.nl
}

check for

updates

Citation: van der Zee, R.B.;

Uilenburg, N.N.;

van der Ploeg, C.P.B.; Dirks, E.

Prevalence of Hearing Loss in Dutch

Newborns; Results of the Nationwide

Well-Baby Newborn Hearing

Screening Program. Appl. Sci. 2022,

12, 2035. https://doi.org/10.3390/

app12042035

Academic Editors: Ronen Perez

and Anton Civit

Received: 7 January 2022

Accepted: 11 February 2022

Published: 16 February 2022

Publisher's Note: MDPI stays neutral with regard to jurisdictional claims in published maps and institutional affiliations.

Copyright: (C) 2022 by the authors. Licensee MDPI, Basel, Switzerland. This article is an open access article distributed under the terms and conditions of the Creative Commons Attribution (CC BY) license (https:// creativecommons.org/licenses/by/ $4.0 /)$.
Abstract: Background: Few studies report prevalence rates of hearing loss in newborns for nationwide populations. The Dutch well-baby newborn hearing screening covers almost all eligible children and has high participation rates for follow-up screening rounds and diagnosis. This allows calculating reliable prevalence rates of permanent neonatal hearing loss specified by severity. Methods: Results from the well-baby newborn hearing screening program and diagnostic follow-up of referred children from 2015 to 2019 were included in calculating prevalence rates. Hearing loss was classified according to the degree of severity. Results: A total of $99.7 \%$ of 833,318 children eligible for screening were included. A total of $0.3 \%$ were referred for audiological diagnostics. Permanent bilateral hearing loss of $\geq 40 \mathrm{~dB}$ was diagnosed in $23.7 \%$ of them and unilateral hearing loss in $14.4 \%$. A prevalence rate of 1.23 per 1000 children was found, 0.46 for unilateral hearing loss and 0.76 for bilateral hearing loss. Moderate hearing loss is most common in children with bilateral hearing loss (0.47), followed by profound (0.21) and severe (0.06) hearing loss. In children with unilateral hearing loss, prevalence rates are the highest for profound hearing loss $(0.21)$, followed by moderate (0.16) and severe (0.09) hearing loss. A total of $87.5 \%$ of the children were diagnosed within the age of 3 months. Conclusions: Because of the high quality of the Dutch well-baby hearing screening program, reported results approximate true prevalence rates of permanent hearing loss by severity.

Keywords: neonatal hearing screening; prevalence; bilateral hearing loss; unilateral hearing loss; newborn; severity of hearing loss; deaf; UNHS; population screening program

\section{Introduction}

Prior to establishing newborn hearing screening programs, children with permanent hearing loss showed to have significantly lower language, literacy, and social-emotional outcomes than children without hearing loss [1]. The introduction of newborn hearing screening programs resulted in early identification and early start of intervention and improved developmental outcomes in children with hearing loss [1,2]. Early enrollment to early intervention services leads to better language, literacy, and social-emotional outcomes than later enrollment [1,3-5].

In the Netherlands, the youth health care services have been performing newborn hearing screening since its nationwide implementation in 2006 [6,7]. Newborn hearing screening was implemented in line with the European Consensus Statement on Neonatal Hearing Screening [8]. Most children are screened in a three-stage screening program. They are referred to a speech and hearing center for an audiological assessment after not passing the screening for the third time. There is a separate screening program for children in neonatal intensive care units (NICU) in the Netherlands, which concerns $2 \%$ of all newborns. In the current study, results from the well-baby hearing screening by the youth health care are reported. To calculate the prevalence of uni- and bilateral hearing loss 
among all newborns in the Netherlands results from the well-baby and NICU populations are combined.

The aim of newborn hearing screening is to identify children with a permanent hearing loss with a minimum of $40 \mathrm{~dB}$ in one or both ears in order to ensure that intervention can start early. The Joint Committee on Infant Hearing has recommended that newborn babies should receive a hearing screening by 1 month of age, a definitive diagnosis of hearing loss by 3 months of age, and enrollment in early intervention by 6 months of age [9]. These recommendations are commonly referred to as the 1-3-6 guidelines. These guidelines are also followed in the Netherlands, except for completion of screening within the first month of life. In the Netherlands, most children are born at home or in a maternity ward from which they are usually discharged within $24 \mathrm{~h}$. Therefore, approximately $75 \%$ of all children are screened in the home environment [10]. For the other children, screening takes place at a well-baby clinic, during a special visit for hearing screening when babies are about 3 weeks old. Therefore, the one-month goal that is set in the international guidelines is extended to 6 weeks in the Netherlands. Since its implementation, the Dutch newborn hearing screening program is very stable and of high quality, with high coverage for each stage of screening and diagnostic testing, low referral rates, and timely screening and diagnosis [10-15]. This enables reliable statements about prevalence rates of hearing loss. Nationwide studies on the prevalence of permanent hearing loss specified by the severity of hearing loss are scarce. The current study aims at reporting the prevalence of permanent uni- and bilateral hearing loss specified by the severity of hearing loss in a well-baby population. The results from screening to the diagnosis of the well-baby hearing screening program in the Netherlands from 2015 to 2019 will be presented.

\section{Materials and Methods}

\subsection{Screening Protocol}

Two screening methods are used in the Netherlands: the otoacoustic emission (OAE) method and the automated auditory brainstem response (A-ABR) method. Both the OAE and the A-ABR screening devices use a threshold of $40 \mathrm{~dB}$ to detect hearing loss. Children are screened in three stages: if a child does not pass the first OAE screening, a second OAE screening follows. If a child does not pass the second OAE screening for one or both ears, a third screening with A-ABR is carried out. In rare cases, this screening path is shortened. There is a 4-to-7-day period between each screening session. If, after the A-ABR screening, satisfactory results for one or both ears have not been obtained, the child is referred to a speech and hearing center for further audiological diagnostics. This screening procedure should be completed within 42 days of birth. Children who are hospitalized (but not in the NICU) for a long period after birth follow a separate hearing screening protocol. This is also carried out by youth health care. The quality of the newborn hearing screening program is closely monitored, on a regional level by the youth health care organizations themselves as well as on a national level by The Netherlands Organization for Applied Scientific Research (TNO) at the commission of the National Institute for Public Health and the Environment, Center for Population Screening Program (RIVM-CvB), and discussed regularly.

\subsection{Diagnostics}

At the speech and hearing center, diagnostic audiological tests are performed in accordance with a national diagnostic protocol for neonates. Currently, there are 27 centers in the Netherlands where neonatal diagnostics are performed. The aim is to have completed all diagnostic hearing testing before the age of 3 months. The results of the diagnostic tests are reported to the Dutch Foundation for the Deaf and Hard of Hearing Child in order to monitor the well-baby hearing screening program. To classify children by degree of hearing loss, we used a classification based on the 1991 classification system of the World Health Organization [16], with exception of the boundary values. These were classified as indicated in Table 1. 
Table 1. Classification of hearing loss in the better ear.

\begin{tabular}{cc}
\hline Grade of Impairment & Hearing Loss \\
\hline Normal hearing & $<40 \mathrm{~dB}$ \\
Moderate impairment & $40-60 \mathrm{~dB}$ \\
Severe impairment & $60-80 \mathrm{~dB}$ \\
Profound impairment & $>80 \mathrm{~dB}$ \\
\hline
\end{tabular}

\subsection{Data Collection}

Data on audiological diagnosis, degree of hearing loss, and timeliness of the diagnosis are extracted from the diagnostic results of the speech and hearing centers, which are stored in the national register of well-baby hearing screening diagnostics. Data on the screening program were obtained from national monitoring reports on neonatal hearing screening from TNO (2015-2019) [10,12-15]. Informed consent was obtained from the parents of all subjects involved in the study.

\section{Results}

From 2015 to 2019, 833,318 well-babies within the Dutch population were eligible for the newborn hearing screening, and 830,696 (99.7\%) participated. A total of $0.3 \%$ of this population ( 2835 children) did not pass the hearing screening. These children were referred to a speech and hearing center for further audiological diagnostics. Diagnostic results are known for $94.6 \%$ of these children (2682 children). Reasons for missing data on the diagnostic results of the 153 children are: missing reports from the speech and hearing center $(57.5 \%)$, not visiting the speech and hearing center for diagnostic testing $(32.7 \%)$, no parental permission for using the diagnostic results $(7.2 \%)$, diagnostic testing was not possible because of severe medical problems $(1.3 \%)$ and children who passed away (1.3\%). From the 2682 children with complete diagnostic results, $23.7 \%$ are diagnosed with bilateral hearing loss of at least $40 \mathrm{~dB}$ and $14.4 \%$ with unilateral hearing loss. This leads to a prevalence rate within well-babies of 0.46 per 1000 for unilateral hearing loss and 0.76 for bilateral hearing loss. An overall prevalence rate of 1.23 per 1000 children was detected for a permanent hearing loss in one or both ears. In $61.9 \%$ of the children, no permanent hearing loss was found, although temporary conductive hearing losses or hearing losses just below $40 \mathrm{~dB}$ were often present. An overview of these results is presented in Figure 1. In Table 2, the results are presented for each year separately.

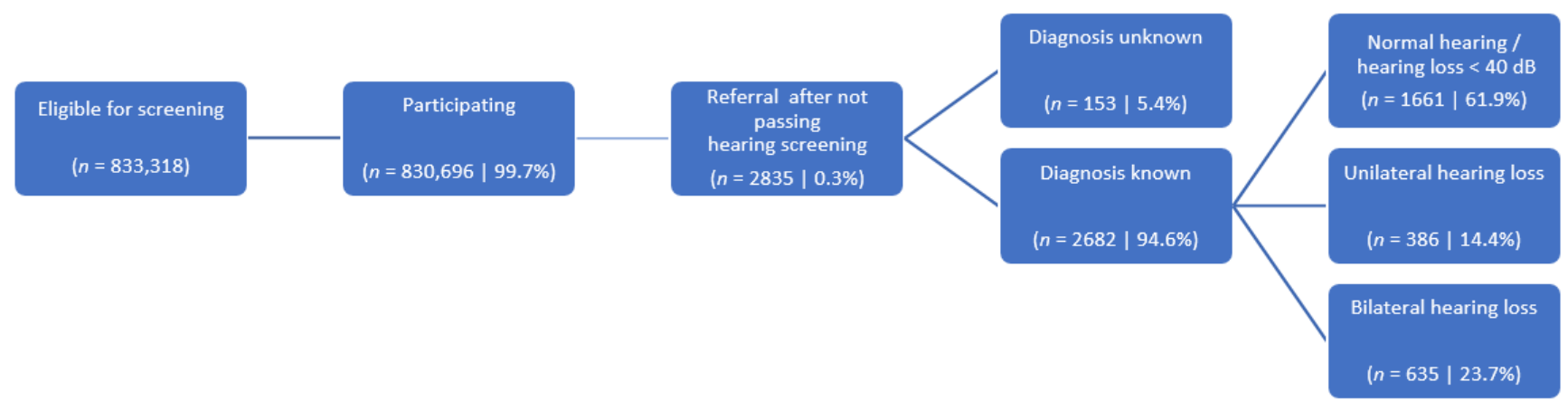

Figure 1. An overview of the results of the national well-baby hearing screening from 2015 to 2019. 
Table 2. Annual diagnostic results after well-baby hearing screening from 2015 to 2019.

\begin{tabular}{|c|c|c|c|c|c|c|c|c|c|c|c|c|}
\hline & \multicolumn{2}{|c|}{2015} & \multicolumn{2}{|c|}{2016} & \multicolumn{2}{|c|}{2017} & \multicolumn{2}{|c|}{2018} & \multicolumn{2}{|c|}{2019} & \multicolumn{2}{|c|}{ Total } \\
\hline & $n$ & $\%$ & $n$ & $\%$ & $n$ & $\%$ & $n$ & $\%$ & $n$ & $\%$ & $n$ & $\%$ \\
\hline Normal hearing/HL $<40 \mathrm{~dB}$ & 311 & 61.5 & 319 & 61.9 & 358 & 65 & 325 & 58.5 & 348 & 62.8 & 1661 & 61.9 \\
\hline Unilateral HL & 82 & 16.2 & 68 & 13.2 & 74 & 13.4 & 85 & 15.3 & 77 & 13.9 & 386 & 14.4 \\
\hline Bilateral HL & 113 & 22.3 & 128 & 24.9 & 119 & 21.6 & 146 & 26.3 & 129 & 23.3 & 635 & 23.7 \\
\hline Total & 506 & & 515 & & 551 & & 556 & & 554 & & 2682 & \\
\hline
\end{tabular}

\subsection{Severity of Hearing Loss}

For children with unilateral hearing loss, a moderate hearing loss was diagnosed in $35.0 \%$ of the children, a severe hearing loss in $18.0 \%$ of the children, and a profound hearing loss in $44.8 \%$ of the children. Within the group of children with bilateral hearing loss, most of the children were diagnosed with moderate hearing loss (62.0\%). A severe hearing loss was diagnosed in $8.5 \%$ of the children and profound hearing loss in $28.0 \%$ of the children. Results are presented in Table 3.

Table 3. Prevalence of hearing loss $\geq 40 \mathrm{~dB}$ by severity in the well-baby population of the Netherlands in 2015-2019 ( $n=833,318$ children, number $(n)$ and prevalence $(\%)$ per 1000 eligible children).

\begin{tabular}{ccccccc}
\hline Severity & \multicolumn{2}{c}{ Unilateral HL } & \multicolumn{2}{c}{ Bilateral HL } & \multicolumn{2}{c}{ Total } \\
\hline & $\boldsymbol{n}$ & \%o & $\boldsymbol{n}$ & \%o & $\boldsymbol{n}$ & \%o \\
\hline Moderate & 135 & 0.16 & 394 & 0.47 & 529 & 0.63 \\
Severe & 72 & 0.09 & 54 & 0.06 & 126 & 0.15 \\
Profound & 173 & 0.21 & 178 & 0.21 & 351 & 0.42 \\
Unknown & 6 & 0.00 & 9 & 0.00 & 15 & 0.01 \\
\hline
\end{tabular}

\subsection{Timeliness of Diagnosis}

Diagnostic testing after the hearing screening should be completed before the child is 3 months of age. In the period from 2015 to $2019,87.5 \%$ of the referred children received their diagnosis in time. For $87.2 \%$ of the children without permanent hearing loss, the diagnostic trajectory was finished before the age of 3 months. In Table 4 , data on the timeliness of diagnosis are presented, categorized by severity of hearing loss. In the group of children with a profound bilateral hearing loss, $98.3 \%$ of the children were diagnosed before they were 3 months old. For children with moderate bilateral hearing loss, this percentage is slightly less, and $82.1 \%$ of these children received their diagnosis on time. A timely diagnosis for children with a profound unilateral hearing loss was found in $93.0 \%$ of the children, compared to $84.3 \%$ of children with a moderate unilateral hearing loss.

Table 4. Timeliness of diagnosis categorized by severity of hearing loss ${ }^{1}$.

\begin{tabular}{ccccc}
\hline & \multicolumn{2}{c}{ Unilateral HL } & \multicolumn{1}{c}{ Bilateral HL } \\
\hline & $n$ & \% Diagnosed within 3 Months & $\boldsymbol{n}$ & \% Diagnosed within 3 Months \\
\hline Moderate & 134 & 84.3 & 391 & 82.1 \\
Severe & 72 & 91.7 & 54 & 85.2 \\
Profound & 172 & 93.0 & 178 & 98.3 \\
Unknown & 6 & 100.0 & 9 & 77.8 \\
\hline Total & 384 & 89.8 & 632 & 86.9 \\
\hline
\end{tabular}

${ }^{1}$ Data from 5 children are missing because the date of diagnosis is lacking.

\section{Discussion}

In order to determine the prevalence rate of hearing loss of newborns in the Netherlands, all Dutch well-babies born in 2015-2019 were investigated. A total prevalence rate of 1.23 per 1000 newborns was found for a permanent hearing loss of $\geq 40 \mathrm{~dB}$ in one or both ears. The prevalence for permanent bilateral hearing loss was 0.76 per 1000 newborns, 
and for unilateral hearing loss, 0.46 per 1000 . The current study reported on the data of the well-baby hearing screening program, which includes $98 \%$ of all newborns. The remaining $2 \%$ of the newborns are screened within the NICU program. Annual reports of the NICU hearing screening program of the same time period as the current study (2015-2019) reveal a prevalence of permanent hearing loss of $\geq 40 \mathrm{~dB}$ in one or both ears of 20.92 per 1000 NICU babies [17-21]. Combining our findings with the NICU results over the same time period leads to a prevalence rate of bilateral hearing loss in the complete Dutch newborn population of 1.22 per 1000 children and 0.63 per 1000 for unilateral hearing loss. This number is comparable to other studies reporting the prevalence of permanent hearing loss in newborns [22-26]. Recently, two meta-analyses reported on the prevalence of permanent hearing loss in newborns worldwide [22,23]. Bussé, Hoeve, Nasserinejad, Mackey, Simonsz and Goedegebure [23] reported a prevalence of bilateral hearing loss of 1.33 per 1000 and a prevalence of unilateral hearing loss of 0.78 per 1000 newborns. Butcher, Dezateux, Cortina-Borja and Knowles [22] reported a prevalence of bilateral permanent hearing loss $\geq 26 \mathrm{~dB}$ of 1.1 per 1000 newborns. Included studies were not nationwide and varied in sample size, the definition of hearing loss, quality of audiometric testing, and number of newborns that were lost to follow-up.

The present study indicates that bilateral hearing loss is more prevalent than unilateral hearing loss in newborns. Nevertheless, there is a considerable number of newborns with unilateral hearing loss. In the Netherlands, family-centered early intervention is only provided to children with a permanent bilateral hearing loss of $\geq 40 \mathrm{~dB}$. However, research shows that children with unilateral hearing loss are also at risk for difficulties in their speech and language development and social-emotional development $[27,28]$. The Joint Committee on Infant Hearing, therefore, recommends early intervention for children with hearing loss as well [9]. The current data reveal that there is a substantial group of children with unilateral hearing loss in the Netherlands who might benefit from family-centered early intervention.

In the literature, only a few studies reported on the prevalence of hearing loss by severity $[24,25,29,30]$. In line with these previous studies, the current findings showed that moderate hearing loss was more prevalent than severe and profound hearing loss. Within the group of children with hearing loss, a moderate hearing loss was even more prevalent than severe and profound hearing loss put together. Despite this, research on children with moderate hearing loss has been less frequent in comparison to severe and profound hearing losses [31]. Fortunately, in the last years, more research has been conducted on children with moderate hearing loss [32-34], which contributes to our knowledge on the development of this group of children and the interventions needed.

While many newborn hearing screening programs worldwide are dealing with high percentages of lost to follow-up during screening and diagnostic testing [22,23], follow-up rates within the Dutch well-baby program are high. Participation is $99.5 \%-99.8 \%$ per screening round, and diagnostic results were lacking for only $5.4 \%$ of the children. Even among these, most children did visit the speech and hearing center, but data on their diagnosis were missing, or parents did not provide permission to share the results. For only 50 children $(1.8 \%)$, it is known that they were truly lost to follow-up. This indicates that the current prevalence data approximate the true prevalence of permanent hearing loss in newborns. Still, as the aim of the screening program is to identify all children with hearing loss, it remains important to obtain insight into the reasons why parents do not visit the speech and hearing center for diagnostic testing of their child.

In order to provide children with hearing loss with the best developmental opportunities, it is important to diagnose them timely (before the age of 3 months), so intervention can start early. Of all children with permanent bilateral hearing loss in the current study, $86.9 \%$ received their diagnosis timely. The current findings indicate that completion of the diagnosis for children with a moderate hearing loss is slightly delayed compared to more severe hearing losses. This is in line with the results of a previous study on the Dutch newborn hearing screening population from 2014 [35]. According to Bosman and 
Goedegebure [35], a conductive component within the hearing loss is one of the main reasons for a delay in diagnosing a permanent hearing loss. Future research could examine the reasons for a delay in diagnosing hearing loss in a larger population. Furthermore, it would be interesting to investigate the start of intervention for the current study population. That would provide us with more insight about meeting the 1-3-6 goal in the Netherlands.

A limitation of the current study is that only data from the well-baby population were used to report on the severity of the hearing loss. While these data were combined with results from children screened in the NICU to calculate Dutch national prevalence rates of uni- and bilateral hearing loss of at least $40 \mathrm{~dB}$, the information on the severity of hearing loss in the NICU population was not available. With these data, nationwide prevalence rates by the severity of hearing loss in the complete Dutch neonatal population could be provided. Presumably, hearing loss in children from the NICU is more severe than in the general population due to possible additional disabilities or syndromes.

Because of the high follow-up rates of the Dutch well-baby hearing screening program, we were able to report results that approximate true prevalence rates of permanent hearing loss. Prevalence rates were 0.76 and 0.46 per 1000 well-babies for bilateral and unilateral hearing loss, respectively. Including children from the NICU, national prevalence rates can be provided. These are 1.23 and 0.63 for bilateral and unilateral hearing loss of $\geq 40 \mathrm{~dB}$, respectively.

Author Contributions: Conceptualization, R.B.v.d.Z. and N.N.U.; methodology, R.B.v.d.Z. and N.N.U.; formal analysis, R.B.v.d.Z.; writing—original draft preparation, R.B.v.d.Z.; writing—review and editing, N.N.U., C.P.B.v.d.P. and E.D.; supervision, N.N.U. and E.D.; project administration, R.B.v.d.Z.; funding acquisition, no additional funding was required. All authors have read and agreed to the published version of the manuscript.

Funding: This research received no external funding.

Institutional Review Board Statement: The study was conducted in accordance with the Declaration of Helsinki. The study was approved by the NSDSK Institutional Ethics Committee, approval number 2022002.

Informed Consent Statement: Informed consent was obtained for all subjects involved in the study.

Data Availability Statement: Data are stored in the newborn hearing screening database that is maintained by the NSDSK.

Conflicts of Interest: The authors declare no conflict of interest.

\section{References}

1. Yoshinaga-Itano, C.; Manchaiah, V.; Hunnicutt, C. Outcomes of universal newborn screening programs: Systematic review. J. Clin. Med. 2021, 10, 2784. [CrossRef] [PubMed]

2. Nelson, H.D.; Bougatsos, C.; Nygren, P. Universal newborn hearing screening: Systematic review to update the 2001 US Preventive Services Task Force Recommendation. Pediatrics 2008, 122, e266-e276. [CrossRef] [PubMed]

3. Meinzen-Derr, J.; Wiley, S.; Choo, D.I. Impact of early intervention on expressive and receptive language development among young children with permanent hearing loss. Am. Ann. Deaf. 2011, 155, 580-591. [CrossRef] [PubMed]

4. Moeller, M.P. Early intervention and language development in children who are deaf and hard of hearing. Pediatrics 2000, 106, e43-e52. [CrossRef] [PubMed]

5. Yoshinaga-Itano, C.; Sedey, A.L.; Coulter, D.K.; Mehl, A.L. Language of early- and later-identified children with hearing loss. Pediatrics 1998, 102, 1161-1171. [CrossRef]

6. Uilenburg, N.; Kauffman-de Boer, M.; van der Ploeg, K.; Oudesluys-Murphy, A.M.; Verkerk, P. An implementation study of neonatal hearing screening in the Netherlands. Int. J. Audiol. 2009, 48, 108-116. [CrossRef]

7. van der Ploeg, C.P.B.; Uilenburg, N.N.; Kauffman-de Boer, M.A.; Oudesluys-Murphy, A.M.; Verkerk, P.H. Newborn hearing screening in youth health care in the Netherlands: National results of implementation and follow-up. Int. J. Audiol. 2012, 51, 584-590. [CrossRef]

8. Grandori, F. The European consensus development conference on neonatal hearing screening (Milan, May 15-16, 1998). Arch. Otolaryngol.-Head Neck Surg. 1999, 125, 118. [CrossRef]

9. Joint Committee on Infant Hearing. Year 2019 position statement: Principles and guidelines for early hearing detection and intervention programs. J. Early Hear. Detect. Interv. 2019, 4, 1-44. 
10. van der Ploeg, K.; Wins, S.; Verkerk, P. Neonatale Gehoorscreening Door de Jeugdgezondheidszorg. Monitor over 2019; TNO: Leiden, The Netherlands, 2020. Available online: https:/ / www.pns.nl/documenten/monitor-neonatale-gehoorscreening-2019 (accessed on 3 January 2022).

11. Uilenburg, N.; Van der Ploeg, C.; Van der Zee, R.; Meuwese-Jongejeugd, A.; Van Zanten, B. From Neonatal Hearing Screening to Intervention: Results of the Dutch Program for Neonatal Hearing Screening in Well Babies. Int. J. Neonatal Screen. $2018,4,27$. [CrossRef]

12. van der Ploeg, K.; van der Pal, S.; Verkerk, P. Neonatale Gehoorscreening Door de Jeugdgezondheidszorg. Monitor over 2015; TNO: Leiden, The Netherland, 2016. Available online: https://www.pns.nl/documenten/monitoring-neonatale-gehoorscreening-2015 (accessed on 3 January 2022).

13. van der Ploeg, K.; Pot, M.; Verkerk, P. Neonatale Gehoorscreening Door de Jeugdgezondheidszorg. Monitor over 2016; TNO: Leiden, The Netherland, 2017. Available online: https:/ / www.pns.nl/documenten/monitor-neonatale-gehoorscreening-2016 (accessed on 3 January 2022).

14. van der Ploeg, K.; Wins, S.; Verkerk, P. Neonatale Gehoorscreening Door de Jeugdgezondheidszorg. Monitor over 2017; TNO: Leiden, The Netherland, 2018. Available online: https:/ / www.pns.nl/documenten/monitor-neonatale-gehoorscreening-2017 (accessed on 3 January 2022).

15. van der Ploeg, K.; Wins, S.; Verkerk, P. Neonatale Gehoorscreening Door de Jeugdgezondheidszorg. Monitor over 2018; TNO: Leiden, The Netherland, 2019. Available online: https://www.pns.nl/documenten/monitor-neonatale-gehoorscreening-2018 (accessed on 3 January 2022).

16. World Health Organization. Report of the Informal Working Group on Prevention of Deafness and Hearing Impairment Programme Planning, Geneva, 18-21 June 1991; World Health Organization: Geneva, Switzerland, 1991.

17. de Graaff-Korf, K.S.; Wins, S.; van Dommelen, P.; van Straaten, H.L.M.; Verkerk, P.H. Jaarverslag Neonatale Gehoorscreening in de Neonatale Intensive Care Units 2015; Isala: Zwolle, The Netherlands, 2017.

18. de Graaff-Korf, K.S.; Wins, S.; van Dommelen, P.; van Straaten, H.L.M.; Verkerk, P.H. Jaarverslag Neonatale Gehoorscreening in de Neonatale Intensive Care Units 2016; Isala: Zwolle, The Netherland, 2018. Available online: https:/ /docplayer.nl/124712056Jaarverslag-neonatale-gehoorscreening-in-de-neonatale-intensive-care-units.html (accessed on 3 January 2022).

19. de Graaff-Korf, K.S.; Wins, S.; van Dommelen, P.; van Straaten, H.L.M.; Verkerk, P.H. Jaarverslag Neonatale Gehoorscreening in de Neonatale Intensive Care Units 2017; Isala: Zwolle, The Netherland, 2019. Available online: https://www.isala.nl/media/26698/20 17-jaarverslag-nicu-neonatale-gehoorscreening.pdf (accessed on 3 January 2022).

20. de Graaff-Korf, K.S.; Wins, S.; van Dommelen, P.; van Straaten, H.L.M.; Verkerk, P.H. Jaarverslag Neonatale Gehoorscreening in de Neonatale Intensive Care Units 2018; Isala: Zwolle, The Netherland, 2020. Available online: https://www.isala.nl/media/29744/20 18-jaarverslag-nicu-neonatale-gehoorscreening-20191210def.pdf (accessed on 3 January 2022).

21. de Graaff-Korf, K.S.; Wins, S.; van Dommelen, P.; Verkerk, P.H. Jaarverslag Neonatale Gehoorscreening in de Neonatale Intensive Care Units 2019; Isala: Zwolle, The Netherland, 2021. Available online: https:/ /www.isala.nl/media/30602/2019-jaarverslag-nicuneonatale-gehoorscreening.pdf (accessed on 3 January 2022).

22. Butcher, E.; Dezateux, C.; Cortina-Borja, M.; Knowles, R.L. Prevalence of permanent childhood hearing loss detected at the universal newborn hearing screen: Systematic review and meta-analysis. PLoS ONE 2019, 14, e0219600. [CrossRef] [PubMed]

23. Bussé, A.M.; Hoeve, H.L.; Nasserinejad, K.; Mackey, A.R.; Simonsz, H.J.; Goedegebure, A. Prevalence of permanent neonatal hearing impairment: Systematic review and Bayesian meta-analysis. Int. J. Audiol. 2020, 59, 475-485. [CrossRef] [PubMed]

24. Uus, K.; Bamford, J. Effectiveness of population-based newborn hearing screening in England: Ages of interventions and profile of cases. Pediatrics 2006, 117, e887-e893. [CrossRef] [PubMed]

25. Mehl, A.L.; Thomson, V. The Colorado newborn hearing screening project, 1992-1999: On the threshold of effective populationbased universal newborn hearing screening. Pediatrics 2002, 109, e7. [CrossRef] [PubMed]

26. Mehra, S.; Eavey, R.D.; Keamy, D.G., Jr. The epidemiology of hearing impairment in the United States: Newborns, children, and adolescents. Otolaryngol.-Head Neck Surg. 2009, 140, 461-472. [CrossRef]

27. Anne, S.; Lieu, J.E.C.; Cohen, M.S. Speech and language consequences of unilateral hearing loss: A systematic review. Otolaryngol.Head Neck Surg. 2017, 157, 572-579. [CrossRef]

28. Laugen, N.J.; Jacobsen, K.H.; Rieffe, C.; Wichstrom, L. Social skills in preschool children with unilateral and mild bilateral hearing loss. Deaf. Educ. Int. 2017, 19, 54-62. [CrossRef]

29. Antoni, M.; Rouillon, I.; Denoyelle, F.; Garabédian, E.-N.; Loundon, N. Newborn hearing screening: Prevalence and medical and paramedical treatment of bilateral hearing loss in a neonatal series in the Ile-de-France region of France. Eur. Ann. Otorhinolaryngol. Head Neck Dis. 2016, 133, 95-99. [CrossRef]

30. Neumann, K.; Gross, M.; Böttcher, P.; Euler, H.A.; Spormann-Lagodzinski, M.; Polzer, M. Effectiveness and efficiency of a universal newborn hearing screening in Germany. Folia Phoniatr. Logop. 2006, 58, 440-455. [CrossRef]

31. Moeller, M.P.; Tomblin, J.B. An introduction to the Outcomes of Children with Hearing Loss study. Ear Hear. 2015, 36, 4S-13S. [CrossRef]

32. Dirks, E.; Stevens, A.; Kok, S.; Frijns, J.; Rieffe, C. Talk with me! Parental linguistic input to toddlers with moderate hearing loss. J. Child Lang. 2020, 47, 186-204. [CrossRef] [PubMed]

33. Tomblin, J.B.; Harrison, M.; Ambrose, S.E.; Walker, E.A.; Oleson, J.J.; Moeller, M.P. Language outcomes in young children with mild to severe hearing loss. Ear Hear. 2015, 36, 76S-91S. [CrossRef] [PubMed] 
34. Netten, A.P.; Rieffe, C.; Soede, W.; Dirks, E.; Korver, A.M.H.; Konings, S.; Briaire, J.J.; Oudesluys-Murphy, A.M.; Dekker, F.W.; Frijns, J.H.M.; et al. Can you hear what I think? Theory of mind in young children with moderate hearing loss. Ear Hear. 2017, 38, 588-597. [CrossRef] [PubMed]

35. Bosman, A.; Goedegebure, A. Evaluatie Vervolgtraject Neonatale Gehoorscreening 2014. VHZ 2019. Available online: https: / /vhz-online.nl/evaluatie-vervolgtraject-neonatale-gehoorscreening-2014 (accessed on 3 January 2022). 